\title{
The Roles of Mainstream Schooling and Shadow Education in English Language Teaching: A Case Study in Hong Kong
}

\author{
Yuksai Nam ${ }^{1, ~ *, ~ K a w a ~ C h a n ~}{ }^{2}$ \\ ${ }^{1}$ Overseas Education College, Xiamen University, Xiamen, China \\ ${ }^{2}$ Department of Education, University of Bath, Bath, United Kingdom \\ Email address: \\ evachuinam@gmail.com (Y. Nam),kwc40@bath.ac.uk(K. Chan) \\ ${ }^{*}$ Corresponding author
}

To cite this article:

Yuksai Nam, Kawa Chan. The Roles of Mainstream Schooling and Shadow Education in English Language Teaching: A Case Study in Hong Kong. Education Journal. Vol. 8, No. 1, 2019, pp. 16-26. doi: 10.11648/j.edu.20190801.13

Received: January 2, 2019; Accepted: January 21, 2019; Published: February 21, 2019

\begin{abstract}
In this article, the writers employ the Service Quality Gap Model to investigate a social phenomenon that has existed for decades but has taken off recently - Supplementary Education. Being a billion-dollar industry that reaches more than three quarters of students in prominent countries, it has a tangible influence on our education system. By comparing the first three stages of the model with interview recordings with students and teachers, the writer explores the differences between perceptions of the student and the teacher. In particular, the writer focuses on English language teaching, and will answer the following questions: does student motive for studying the language differ from what teachers and tutors think it is? Does teaching material conform to student expectations of what they will be learning? What different roles do traditional institutions and tutoring centres play specifically in ELT; in particular, are they positively supplementary to each other, or are they negatively contrastive and competitive in nature? Findings suggest the longer supplementary education has existed a place, the more likely it indeed is supplementary to formal education.
\end{abstract}

Keywords: Supplementary Education, Mainstream Schooling, English Language Teaching, Service Quality Gap Model

\section{Introduction}

Supplementary private tutoring, or shadow education, refers to individual tutors giving out-of-school teaching to help improve students' results in school. It follows the mainstream curriculum [1], and is growing rapidly in different parts of the world, particularly in Asia [2]. Despite the rising trend that had lasted for at least a few decades, there had not been much research on the subject; collecting data was hard because tutors did not wish to be studied [3]. However, the phenomenon continues to pick up momentum, and is becoming a global issue at present. Visibility becomes clearer and more quality research has been conducted [4].

Researchers have focused on different areas of the phenomenon. Socioeconomically, how is shadow education connected to social stratification [5]? Psychologically, or pedagogically, what are the motives for such education [5]? How effective is such education [6]? Meta-studies that reflect on the research methodologies employed have also been done
[3]. There have also been comparative studies that explore the similarities and differences between schooling and tutoring [7].

However, research is far from complete [8]. There are many things we still do not understand; in particular, what role does schooling and tutoring play in the context of a single subject? Single-subject studies ought to be significant since differences in curricula and syllabi exist, the methods to teach language, logic and thinking, history and memorization, all differ to a large extent. In particular, a focused lens examining English Studies is necessary since it employs different teaching materials and pedagogical approaches than other school subjects. Without a sufficiently sound understanding of the roles schools and private practitioners have on English learning, teaching quality can hardly be elevated or be compromised at worse. This current study serves to fill the hole in this regard.

Many different models have been employed to study shadow education; methods from the biological and psychological disciplines have seen their use [9]. However, 
one can also look at such education from a marketing perspective; after all, private tutoring has gradually been commercialized and some tutoring institutions have risen to be big corporations. In this study, the Service Quality Gap Model [10] is used.

As for the demographic, Hong Kong is chosen for several reasons. First, the tutoring industry is developing very rapidly, and a large number of students, brilliant and underperforming alike, have sought private tutoring. Supply and demand are both high, or in other words, it has been heavily marketized [11]. Second, Hong Kong has a special cultural background; it was colonized by the English until 1997. It is also a location of international and economic importance. Both contribute to the common viewpoint that English is a prestigious language. As such, both culturally and economically, the educational context in Hong Kong provides a fertile fostering ground for in-depth research into the subject.

This study begins with a background of shadow education, attempts to give it a rigorous definition, and gives a literature review. Research questions are also posed in this section. What follows the section concerns the background of Hong Kong; we will outline the cultural characteristics and historical backdrop that make Hong Kong an interesting subject of study. Thereafter, the methodologies employed for this study are listed; in particular, how data is collected, coded and analyzed, how quality is ensured and how ethics is considered. Then the writers present the findings and subsequent discussion of the needs of Hong Kong students through the Service Quality Gap model, and the central question is answered: what is the role played by schools and private institutions in ELT? Finally, the writers conclude with an exploration of possible research directions and outline some limitations of the current study.

\section{Literature Review}

\subsection{Definition}

Supplementary education is also called Shadow Education because it is often masked by the shadow of the mass schooling philosophy that they follow. It shares many characteristics with schooling, yet is often ignored by the government which focuses their attention on schooling [1]. While there is more or less a vague notion of what it is, its definition has not been standardized, and different researchers have given different interpretations [12]. In this paper, the writers choose Bray's interpretation for its wide adoption. According to Bray, supplementary education mainly has three characteristics. First, the subjects that supplementary education is concerned with are academic subjects taught by mainstream schooling, for example the languages, science, mathematics, and the humanities. Sports and music are not included in this category. Second, the aim of supplementary education is not to impart new knowledge, but to consolidate what the student has already learned in school. Thus, classes that teach a new language or something that is outside school syllabi are not included in supplementary education. Third characteristic is the privateness. By privateness, we mean teachers who gain monetary value for their services. Thus, it includes private tutors and private teaching institutions, but excludes volunteers and friends or family members.

\subsection{Recent Development}

Supplementary education started to take its modern form in the 1960s, when its economic influence and social impact were starting to emerge [13]. However, there was not much research on the subject, and there were two reasons for this. First, it did not gain a significant interest from researchers [14]; but second, and more importantly, data collection had been difficult because tutors and students alike were hesitant to give away information regarding their business. A part of the reason is that private tutors are often illegally untaxed, and students feel that their added education may imply they are gaining an unfair advantage.

However, this has started to change at the turn of the century, where the practice of supplementary education picks up momentum and people start to talk more freely about it. This is evident because a lot of research has taken place [9]. To put the phenomenon in perspective, more than half of the secondary students in Greece have reported taking part in tutorial classes at some point in their education. Burch [15] and Watson [16] have respectively demonstrated similar proportions in North America, South America and Australia. In Asia, in particular, more than $80 \%$ of middle school students have sought supplementary education [17]; this has sufficiently demonstrated that supplementary education is a great force that is shaping our educational sector, and research needs to be conducted to uncover its impacts in depth.

\subsection{Research Gaps}

\subsubsection{Roles of Schooling and Tutoring}

Different aspects of shadow education have been touched on by a number of researchers. Most centres on the wider sociological and economic impact of shadow education [5], and thus we now understand how a student's family background influences their chances of getting supplementary tutoring, and the stems and roots of education inequality. Others have focused on student motive; and we now understand that students seek supplementary education not only because it prepares them better for tests, but also simply because a majority of their friends are doing the same thing [18]. Researchers have also explored how effective tutoring is, and whether it has helped in both the acquisition knowledge and application in exams. On the contrary, there has not been much research that explores the different roles played by the school and tutoring classes; Bray and Kobakhidze [7] once gave a brief outline, including differentiation, partnerships and conflicts, but no more has been said. More research needs to be done to clarify these notions. 


\subsubsection{Focus of Single Subjects}

A lot of research has focused on the school curriculum as a whole, and seldom gives contrast to different subjects. This makes their analysis more or less incomplete, since vastly different syllabi exist between subjects. Language teaching, methods of thinking, and historical events all require different teaching approaches and learning skills.

In this study, we choose English because of its skill-based nature. Unlike the humanities, which are content-based, English cannot be learned only through memorization and deduction, but has to be put into practice. Students can only maintain conversation when they have made use of the language more often than is enough. As noted, there has only been a handful of research carried out on the topic; most notably, Hamid et al. [18] focuses on English learning in regions that are stigmatized as having lower socioeconomic value, and how its quality of tutoring compares with traditional schools. Lee [19] has explored the teaching of English in Korea and Hong Kong, but still little attention was given to the teaching materials and methods of teaching. This paper endeavours to fill these gaps.

\subsubsection{Theoretical Framework}

Many tools from various disciplines have been employed to study the wide social phenomenon of shadow education [9]. The more interesting ones include biology, where the theory of an ecosystem was used to study the differences between studying in schools and under tutors [7]; psychology, where Maslow's Hierarchy of Needs was used to explore why students seek shadow education.

Our paper employs a method from yet another discipline: business. The rationale behind this is that tutoring has evolved from a small individual practice to a large multibillion dollar business nowadays [20]. There are tutorial centres with brands and advertisements of celebrity tutors can be seen everywhere; in this regard, education has become a form of profitable business.

The paradigm that we will be concerned with is the Service Quality Gap Model, first developed in 1985 by three scholars: Parasuraman, Berry and Zeithaml. They defined quality as 'a comparison between expectations and performance'. When the level of expected service (ES) is lower than the level of perceived service (PS), it means expectations exceeded; thereby there is quality surprise. When the level of ES equals that of PS, it means expectations met and there is a satisfactory quality. However, when the level of ES is higher than that of PS, expectations were not met, resulting in an unacceptable quality. The difference between ES and PS is thus named Gaps. There are different aspects of customer expectations, ranging from product design to customer-provider communication; thus there are different kinds of Gaps. Fitzsimmons [21] identified five different gaps, namely 1) Market research gap, 2) Design gap, 3) Conformance gap, 4) Communication Gap and 5) Customer satisfaction Gap. This study focuses on Gaps 1 to 3.

Gap 1: Market Research. Discrepancy between customer expectation and actual service sometimes stems from a lack of understanding on the provider's part. If they do not have a solid grasp of what the customer wants from their purchase, they cannot deliver a satisfactory result. In a sense, this is an overarching gap that oversees other aspects of the model. Specifically, in our case, this gap may appear if teachers and tutors do not understand students' true needs of studying English - whether to accommodate the latest exam or to develop a solid basis for further development, etc.

Gap 2: Design. Even when student need is clear to the instructor, a gap may still exist if there is a discrepancy between a student's expectation of what he will be taught and what is actually taught. In other words, curriculum design and teaching materials may not match up to the student's expectations.

Gap 3: Conformance. Even when market research gaps and design gap are minimized, and service design matches the student's expectations, dissatisfaction may still arise if the provider fails to conform to their own design. For example, if teacher quality is not satisfactory due to insufficient training, inefficient teaching approaches, or unorthodox thinking, then what was by design might not be delivered effectively.

\subsection{Research Questions}

Following the outline above of the three service gaps, three questions are of prime importance:

(Market Research) What is the aim of students seeking supplementary education? What do they hope to get out of it?

(Design) How is the syllabus designed to cater to the needs from question 1 ?

(Conformance) What role do traditional schools and private tutoring play, respectively, in the education of the English language?

\section{Context}

Our location of study is Hong Kong; below outlines the backdrop that defines the region that exists today.

\subsection{Historical}

The full name of Hong Kong is Hong Kong Special Administrative Region, which enjoys a special status as a region of high autonomy. The reason for this is because it was an English colony for over a century, and was only returned to China in 1997. The interwoven cultures that exist in Hong Kong are why English is given a high regard in the region. Besides, the Basic Lawstipulatesthat English be taught as an official language of the region. This provides a sound explanation for the motivation of students to learn English well.

\subsection{Cultural}

Hong Kong, as a part of China, consists over $90 \%$ of Chinese residents. In China, an over 4000-year heritage dictates that examination is the road to success. A good result would have entitled one to a high government position dating 
as far back as Confucius [11]. This could provide a cultural factor as to why students are anxious to seek supplementary education in Hong Kong.

\subsection{Demographic}

Apart from the desire to seek more education, students in general are also able to afford it because Hong Kong is a rather affluent city. According to a study by Bray and Kwok [14], there is a positive correspondence between salary and the amount parents are willing to invest in their children's education. Government statistics have shown that the per capita GDP in Hong Kong reached over US\$40,000 in 2014, and the sufficient economic power may be another reason for the explosion in tutoring services.

\subsection{Education System}

The secondary education system underwent a dramatic change 10 years ago, where the government decided to change the high school curriculum from a 5-2-3 system to a 3-3-4 system.

What this means is, instead of spending 5 years of junior high and 2 years of senior high for 2 exams respectively to get admitted tocollege, students now take 3 years of junior high and 3 more years of senior high for one exam of the Hong Kong Diploma of Secondary School (HKDSE) at the end of grade 12 for admission.

While this is normal practice in a lot of other countries, it is a dramatically new system for Hong Kong students and teachers alike, and many struggled to get accustomed to the system. The change from 2 examinations to 1 also meant that the single exam would be their final verdict, and their success afterward depended heavily on their achievement during it. Thus students were eager to seek supplementary tutoring [22] and parents were equally eager to support their children [23].

\section{Methodology}

This paper primarily utilizes a qualitative analysis of subject response. The reason for picking a non-numerical treatment is that in this study, student perception is of primary importance; we want to understand English learning as experienced by Hong Kong students themselves. Exploring their points of view and their own interpretations is the most suitable in this regard.

We perform case studies. The rationale behind this is the strong support for inductive analysis. Single cases are not only dots of a spectrum, but they provide a strong blueprint for researchers to understand other similar phenomena [24]. The number of cases is 15 in total, including 12 Grade 11 students and 3 secondary school teachers.

Non-probabilistic sampling is used in this study in order to acquire in-depth information about specific groups of students; participants fall into two categories: teachers and students. For teachers, the writershave employed convenience sampling and chosen three secondary school teachers and two university lecturers on one of the writers own accord; there are both benefits and deficiencies to this method. The candidates are likely to be more active when they impart information, but issues of credibility cannot be ignored. For students, the writers have employed criterion sampling, and chosen 12 students who met the following criteria: 1) They must be in Grade 11;2) They must have received supplementary education for the past 12 months. Specifically, grade 11 was selected because they were the immediate batch to take the HKDSE exam, and likely the most relevant group of student sample to study with. Credibility is ensured by contacting their tutors.

Three methods of instrumentation are employed: interview, observation and document analysis. Interview is our main method of approach as interviews are conducted face-to-face; the amount of information gained is not limited by width or depth. Moreover, questions can be asked concisely and direct, unhindered responses can be obtained. This is particularly important in our study, because we want to explore the experience of learning from our subjects' point of view. Individual interviews were performed with the teachers. Group interviews were performed with the students; while some individuality may be lost to a little extent, the writer thinks the benefits outweigh the potential loss. In many interviews, students may be too shy to divulge their honest opinions [9] by putting them together in a group with peers sharing similar experiences, it would encourage them to speak more openly about their circumstances.

To supplement the data obtained from the self-accounts of teachers and students, which provide an in-depth exploration of their own experience, the writers also observed a few traditional classes in a secondary school. This supplement can further validate the reported data by cross-referencing it with the writers' own observations. The downside to this method is what is known as the Hawthorne Effect, where students deviate from normal behaviour when they are in knowledge of being observed. To this end, the writers have employed some methods to minimize the effects.

The final instrument is to examine documents. However, document examination has its own benefits and downside. Most notably, documents are a form of secondary information, and its validity is not as high as direct interviews and observation. However, in the case where the latter fails, where private tutors may wish to remain anonymous and keep their teaching materials as a trade secret, documents provide a large amount of information to fill the hole. Care has been taken to ensure 'authenticity, meaning, representativeness and credibility' as emphasized by Scott [25].

\subsection{Data Collection}

Interviews with the teachers were held at their private offices with their consent. All procedures were carefully recorded, and Cantonese was used throughout the interview. They were asked to express their thoughts on student motive of studying English, the roles of schooling and tutoring, and their own experience. Interviews with the students were held at their secondary school with their consent. All procedures 
were carefully recorded, and Cantonese was used throughout the interview. They were also asked to express their opinions on their reasons for studying English, the roles of schooling and tutoring, and their own experience.

For the observation, one of the writers acted as one of the students in a secondary school, joining all their activities. This provides a firsthand experience of the learning experience of students. All observations were jotted in the form of field notes, and carefully organized afterwards as information for later use.

For the document analysis, the writers consulted textbooks and teaching materials from schooling and supplementary tutoring. Both were analyzed carefully to obtain a good comparison. Lastly, official HKDSE exam papers were also consulted, and teaching materials were cross-referenced with official exams to gauge the similarities.

\subsection{Data Analysis}

The study collects mainly qualitative data, and a thematic analysis was chosen to analyze them. The theme was chosen to be the research questions themselves. Creswell [26] defines this method as follows:

(1) Step 1: Organizing and Preparing the Data for Analysis

(2) Step 2: Reading through All Data

(3) Step 3: Coding the Data

(4) Step 4: Interrelating

(5) Step 5: Interpreting the Meaning

Since the interviews were conducted in the students' and teachers' native language, the writers had to translate them into English, and furthermore into written form. It was subsequently scrutinized and keywords were highlighted in accordance with the thematic analysis. The analysis is also computer-assisted, and Office Excel was used to organize the data in a useful form and correlations were identified. The insights from the analysis were then compared with the writers' observations and document analysis. The writers hope that the diversified tools would help put the event in perspective and our understanding of schooling and tutoring would thus deepen.

\section{Findings and Discussion}

This section attempts to answer the research questions. First, a summary of the writer's findings will be presented. Then, the Service Quality Gap Model will help us pinpoint the motives behind students' learning English and how schools and tutors help them achieve this. Lastly, we will explore the roles of schooling and tutoring.

\subsection{Summary of Findings}

Teacher M, who was trained in the universities of Hong Kong, has been teaching for twenty two years. He teaches English at senior forms and trains students for public exams. $\mathrm{He}$ is a relatively traditional teacher because he often insists on the instructions formulated by the secondary school.

Teacher $C$ has 6 years of teaching experience. She is trained in the universities of Hong Kong and England. She teaches English and History at senior forms and taught in an international school for a year. She is an innovative teacher who utilizes different activities with communicative elements.

Teacher F has been teaching for ten years. She is trained at the universities in Hong Kong. She teaches English and Liberal Studies at senior forms. She is a flexible teacher who adjusts her teaching directions according to her students' abilities.

Students vary in the length of receiving supplement education from one month to 21 months. Most of them attend chain-store tutoring centres once a week. All twelve students received a single type of tutoring - lecturing. Researchers in the field have identified and defined a number of tutoring types - some prefer a one-to-one style, some prefer group teaching, and some prefer online tutoring. Each style caters to students of different characteristics and needs, and tutors adept at different styles often have vastly different teaching methods [3]. In view of this, it is crucial that the researcher focus on one aspect of this. In the current study, the writers choose the dominant form of tutoring in Hong Kong - the lecture-type. In this type, tutorial classes essentially mimic the practice of schools; it is a one-to-many teaching style that is held in a classroom.

The second detail to note is that most students prefer studying in a chain-store tutorial centre, while only one opted for regional tutoring service. Most of them claimed that reliability was their main reason for choosing large tutorial centres. All tutorials have a range of 1.5-2.0 hours.

\subsection{Market Research Gap}

As per the central theme of Service Quality Gap Model, Parasuraman et al. [10] defined quality by the difference between a customer's expected service and perceived service. Thus, the first thing for a provider to do is to identify the needs of its target customers. This is the first gap in the model, and is also the overarching gap overlooking the other ones. In the study, the writers identify 5 different motives of Hong Kong students studying English.

\subsubsection{Examinations}

Students and teachers alike unanimously agree that examinations are the main motive for studying English:

Teacher M: Students undergo 6 years of secondary school, studying for the better half of the last three years, all for the same destination: tertiary education. Since HKDSE is the main entrance ticket for them, it is not surprising that they think a good English result will grant them an edge.

Student J: In a lot of university programs, the admissions committee will put extra emphasis on students' abilities in English, doubling or even tripling counting your grade.

This finding is consistent with the writer's understanding of Hong Kong's educational situation and is not at all surprising. However, the writers have observed an interesting inconsistency in students' and teachers' perception. Continuing their line of reasoning, some teachers have 
reached a conclusion that students ONLY see examinations as their need of studying English, but do not understand whether it has other uses at all.

Teacher F: Moreover, I think I can say with confidence that students are only learning English to satisfy university admissions and to satisfy their parents' expectations. On the contrary, if education does not require English as a compulsory subject, I think most of them will not even think of acquiring this language for their own.

This is where the inconsistency lies. During the interviews with the students, writers found that students are actually aware of other uses of English. This will be expressed in detail in the following sections.

\subsubsection{Knowledge Acquisition}

A word of clarification is needed here since the heading contains some ambiguity. This does not mean that students study English for the sake of studying English linguistic knowledge, but they see English as a tool to further their studies in various subjects. As some interviewees pointed out:

Teacher M: In secondary school, English may only be a subject. But in university, it becomes a medium of instruction. Virtually all subjects are taught in English, and if the student has difficulty in English comprehension, he may suffer a huge disadvantage.

Student C: When I enter university, whatever major I decide to study, I am sure I need English in class and in assignments.

Of course, an interesting precondition to their statements is that the students must already have been admitted to a tertiary institution. In this regard, examinations may still be a priority over knowledge acquisition.

Nevertheless, the importance of English as a knowledge gaining tool has been established. A good grasp of the English language is required for a good understanding of university classes, and reference books will also be easier to read. Indeed, most journals published in different parts of the world use English as their main medium, even if it is not their native language [27]; some jargon can also only be found in English and not translated to other languages [28].

\subsubsection{Career}

Teachers and students acknowledge that English is important out in the workforce. Historical and socioeconomic reasons have made English a kind of trade language, a status quo that is not likely to change in the foreseeable future. Many international corporations exist where workers from different areas of the world communicate in English as their common language.

Teacher F: English is important almost in every aspect of work. Even with my position as a secondary school teacher, I need to use English outside class to communicate with some native English teachers.

Student I: I know a lot of older friends and relatives who often need to hold presentations in English in their company.

Student K: Every recruitment advertisement I ever read has cited English as an absolute requirement.
This motive can be further supplemented by literature. Indeed, bilinguals, and especially bilinguals in English, have a much higher edge in the workforce as demonstrated in a study by Baker [29]. Their salaries can differ up to $30 \%$ from monolingual workers.

\subsubsection{Communication}

In a way, this is a generalization of motivefor career mentioned previously. But interviewees have often listed it as one of their main motives of studying English, so the writers decide to list it as an independent heading. While the need of English has already been established for communication in the workforce, interviewees have raised other interesting phenomena. Teacher $\mathrm{M}$ has identified the need especially in the cultural background of Hong Kong.

Teacher M: Hong Kong had been an English colony for the better half of last century. It was open to the world at the time as an opportunity for trade and business. In such an internationalized city, there are ample situations where we need to communicate with foreigners.

Student A: I have a great interest in exchange programs in university as I have heard a great deal about them. When I go abroad, English is a must for people to understand me.

Of course, even with schoolmates, English is sometimes required outside school for social activities. It should come as no surprise that English becomes a common medium to facilitate communication.

\subsubsection{Other Reasons}

The above four reasons were among the most listed ones by the interviewees, but they were by no means exhaustive. Below are some reasons also mentioned in our interviews, which the writers have summarized in point form:

To enjoy foreign entertainment media, such as novels, movies, etc.

To enjoy Western culture through the lens of their language.

Preparation work for future immigration to America.

Summarily, we have defined four major motives and additional individual reasons for studying English. Knowledge of this should minimize the Market Research Gap on the part of both schools and tutors.

\subsection{Service Design Gap}

Of course, minimizing market research gap is not enough if there is not enough action to back it up. Specifically, if the curriculum design and pedagogical approaches do not meet the students' expectations, even if they do cater to their general needs mentioned above, students will still perceive the service as falling short of quality.

\subsubsection{Examinations}

With regard to the primary motive of examination, it is essential to have an understanding of the current HKDSE structure. Document analysis of past papers have shown that the HKDSE English paper consists of four different parts, four so-called 'macro-skills' that involve Reading, Listening, Speaking and Writing. 
Teacher M: The current framework set by our school has always been intended to prepare our students sufficiently for the HKDSE.

Student C: In every class and every set of notes provided by my tutor, there are exam tips and shortcuts that can even bypass inherent English deficiency.

While the exam is projected as examining students' four macro-skills, the writers' closer inspection indicates that each paper is actually not isolated, to which the writers mean that the four skills are tested in an interwoven way rather than individually: grammar skills are required in the reading test; reading skills are required in the listening test when students need to skim data files for relevant information; and listening skills are required in the speaking test. So in a way, the exam is multi-faceted. So our question is: how do schools and tutors cater to this hydra structure of the exam?

In schools, because they are relatively unconstrained by time, and teachers have a relatively high autonomy as to what to teach in class, we have evidence that they cater more to the well-roundedness of students' English abilities as a whole. They not only have a balance of all four skills, but also provide additional reading materials and ad hoc presentations to heighten the general level of students' language proficiency. On the other hand, because tutors have approximately 1-2 hours each week, they do not have the luxury to take care of every facet of students' abilities, and have to prioritize. In particular, students have complained that tutors put much more emphasis on reading and writing, while less on speaking and listening.

Student D: Well, we do have some kind of listening exercise, but it is more in the form of data collection skills; we never have any actual listening task to practice with.

Student F: No speaking practice, ever, in my tutorial classes.

However, according to the interviews, students often prefer grammar lessons from tutorial classes to those at school. As mentioned, school teachers have a rather high degree of autonomy, and their grammar exercises have been reported to be scattered across lessons, and to lack organization and to be rather incomprehensible. On the other hand, tutors effectively organize grammar lessons according to the degree of difficulty, which is greatly appreciated by their students.

One similar practice of schools and tutors is to provide students with English newspaper articles. This became a common practice since the articles were favoured as official examination material.

Student C: My tutor gives me an article every week, sometimes from SCMP (South China Morning Post), and sometimes from New York Times.

In conclusion, schools and tutors are largely examoriented.

\subsubsection{Service Design Gap Concerning Other Needs}

While schools and tutors cater to students' examination needs to a large extent, there are a number of learning items that distinguish themselves from examinations.

Lexical items. Vocabulary also is a rather large focus of both schools and tutorials. Based on the writer's document analysis, introduction of new words, idioms, connectives is very common. In compilation of their notes, tutors classify the new expressions under different categories like teen life, travel, etc.

Student G: During each grammar session, my tutor requires us to recite a list of words

Student I: We learn new words from all the newspaper clippings handed to us.

Practical Writing. Instead of writing argumentative essays like in the examination, quite often teachers and tutors alike will train their students' skills in writing proposals, complaint letters, etc.

Diversity of teaching media. This is limited to schools only; some teachers will utilize modern technologies such as websites and mobile applications to raise students' general interest in English.

As can be seen above, acquiring lexical items caters to student needs of communication and entertainment; practical writing caters to their need for career; and diversity of teaching media provides another form that helps students achieve what they want. In the language of Service Design, the gap is minimized.

\subsection{Conformance Gap}

Design falls into the theoretical side of things, as teachers and tutors construct their teaching plan prior to actual service. But on the practical side, how closely do their actions conform to their own standards?

\subsubsection{Examinations}

Teachers and tutors are no different with their teaching design intended for their students to meet satisfactorily the curriculum. Indeed, both heavily employ the audio-lingual method of teaching. Both provide their students with a large number of exercises for training drills. If any difference needs to be mentioned, it is that exercises from tutors are sometimes repetitive in nature; the same question can appear in order to firmly entrench the information in students' minds. Exercises from teachers are continuous in nature, in which wave after wave of exercises are given to students in preparation for their official examination. Document analysis of the mock papers and actual observation in classes has confirmed this by the writers.

Student D: Once I needed to do the same exercise in a single day because my teacher and tutor just happened to pick the same paper.

Student F: Past papers do not come from only HKDSE you know, we sometimes deal with the ancient HKAL too.

Indeed, it has been mentioned by scholars that examinations are the focus of teachers and tutors [30].

\subsubsection{Conformance Gap Concerning Other Needs}

With regard to the need of communication and others, schooling has been found to perform better than tutorial classes.

Task-based practice. Schools employ these to enhance 
students' daily use of English. There are games and group discussions in some cases, and application of English in daily situations will strengthen their use in future careers and normal communication purposes. Tutoring, on the other hand, does not engage in such activities.

Teacher F: I have tried organizing games that we play as a whole after watching a movie with subtitles.

Interaction. In school, the interaction between students and teachers is a two-way relationship. Teachers not only impart knowledge, but also give opportunities for students to answer questions and elaborate their answers and to express themselves. However, interaction in tutorial classes is strictly one-way, and consists of the tutor explaining lecture materials without student contribution.

Medium of instruction. The only medium of instruction in tutoring is Cantonese, while in schools, it is effectively flexible. (While officially, it is mandated that English be used in class, teachers usually enjoy a high degree of autonomy as to whether or not they follow this mandate)

\subsection{Roles of Schooling and Tutoring}

In this subsection, we will be heavily employing a primitive framework designed by Bray and Kobakhidze [7], since the writers think it is a very good reference point for analysis. They described the roles of schooling and tutoring as 'differentiations, partnerships, and conflicts'. However, their article did not include a lot of elaboration on the specifics. We will make elaborations based on his findings.

\subsubsection{Differentiations}

Schooling - Facilitators. Schooling provides a firm foundation for students to learn. They are responsible for facilitating their learning process, inspiring them, encouraging them, but ultimately, the end goal is to make students a self-learner, motivated enough to sustain their own learning.

Schooling - Nurturers. Motivation for self-learners comes in many forms. One that schooling endeavours to nurture is interest. Making students interested in what they learn is one of the goals of schooling, and teaching in general.

Teacher F: I make my students see beyond grammar rules and memorization of formats. I make them love English.

Schooling - Moral Educators. Effectively, for many students, school is a home away from home. Every day, they spend an average of 8 hours in school, and it plays a huge role not only in their academic development, but also social development and personal wellbeing. In this sense, schools also have a responsibility to impart moral knowledge.

Tutoring - Businessmen. Tutoring is a business first and foremost. It is a for-profit practice and is established largely for monetary gain. In this sense, tutoring relies on marketing and needs attractive packages for their offers and classes.

In conclusion, because of the entirely different premises that they are built on, they have largely differentiated roles.

\subsubsection{Supplementary Relationship}

In form, we can see that the roles of schooling and tutoring are differentiated, but by function, we will learn that there exists a supplementary relationship between them.

Schooling - Sufficient time

Teacher $C$ : In the last three years of their secondary school, a single teacher is responsible for overseeing their entire journey until the exam. I am in the position to understand every one of my students' strengths and weaknesses.

Because of the extended amount of time between students and their school teacher, tailored teaching can be performed that focuses on students' individuality. On the other hand, in tutorial classes, since students typically spend only an average of 1-2 hours per week, and interactions are only oneway, and a typical class easily holds more than 60 people (there are situations where a single class has thousands of students, where most need to watch a 'live broadcast' in an empty room), it is impossible for tutors to know their students well enough to cater to everyone's needs.

A duration of three years nonetheless, students spend more than 8 English lessons each week in school, for a total of more than 6 hours. A lot of time can be allocated to a more complete assignment, while in tutorials, students have reported not having enough time to finish even simple class work.

Teacher M: Listening is an important part of my teaching, and in training students' listening skills, I can replay the tape as many times as I want, and I can also teach them additional knowledge like an analysis of the transcript.

Tutoring - Abundant resources

Student K: In my tutorial class, I am given a set of notes each week that contains vocabulary that I haven't learned before and tips and tricks that I would never have learned in school.

What tutors lack is time, but they have relatively abundant resources to make up for it. Most of the time, a single tutor has a team of helpers behind him to help design lecture notes and practice exams. On the other hand, materials used by school are predetermined by the official syllabus, and textbooks have remained stale no matter how many editions they might undergo.

Teacher F: To my understanding, tutorial centres pride themselves in their accuracy to predict exam questions and directions.

There is a trend in tutorial centreswhich is seldom practiced in schools - question prediction. With examsapproaching, tutors will tell their students which part of the syllabus is likely to appear in the exam. To some students, this can appear very attractive because they may not have the ability or time to study the entire syllabus so they find they have no alternative but to follow their tutor's advice and study only the parts suggested. Of course, the predictions are not without their reason because tutors have enough resources to analyze past papers thoroughly, and technical analysis has shown that it works in a number of cases.

\subsubsection{Competitive Relationship}

However, schooling encompasses the entire city's children 
and teenagers. The supplementary nature may not be an instance in every student's case.

Teacher M: I have pupils who became so confident of themselves after receiving tutoring services that they started napping in my class because they think they can handle everything in the exam. He learned his lesson the hard way.

As implied by the interviewee, the relationship between schools and tutoring may not be as ideal as one would hope for. Instead, it depends much on the student's mindset. If students think that it is a choice between the two of them: having one means being able to discard the other, then the effects are indeed adverse. There are other cases too where conflicts become even more tangible. Some students may use their knowledge gained from tutoring to challenge their teachers; this might very well damage their mutual relationship:

Student D: Newspaper articles and movies are so useless. They have no bearing at all on our exam. Why are we required to do something that does not improve our scores and chances to university? I would rather read my notes than listen to our teacher.

Teacher F: I try to be open-minded about students accepting tutorial classes, and most of the time I am. But sometimes, there will be that one student who measures everything with a scale, and will put you below the tutor that he admires. That is when trouble arises.

Therefore, all in all, the roles between schooling and tutoring are multi-faceted yet conflicting. In an ideal world, they are complementary, and social wellbeing increases because of them, but there are occasions where they can have conflicting interests. After all, students are still young, and sometimes irrationality can intervene.

\section{Conclusion and Implications}

This research started as an attempt to fill a hole in current related research. While there has been research in wider socio-economical implications of tutoring, there is less about the relationship between schools and tutoring, and even less about a single subject like English. This study then sets out to compare both pedagogical approaches and teaching materials in both, employing the Service Quality Gap Model in the process to analyze them.

Under the framework, it is essential that students' expectations and actual service be matched as closely as possible. Thus, market research is done to identify why they want to study English, then design and conformance were performed to explore whether schools and tutors have succeeded in matching their actual practices with their ideas and student expectations. Lastly, the findings have allowed us to understand both the complementary and the conflicting roles that school and tutoring plays. The writers credit Bray for providing the larger framework on which we have based our analysis. The good is both schooling and tutoringare involved in working mutually to cover each other's weaknesses as students' individuality and an abundance of resources can be used to better their English. The bad, however, is students' weight more on tutoring might cause them to have conflicts with their teachers, thus damaging their relationship in the process.

\section{Implications}

In view of micro environment, TESOL practitioners, both teachers and tutors, are strongly urged to learn from each other in this era of high-stakes assessments. In fact, this research shows how schooling and tutoring could gain much more additional advantages to be complementary to each other; hence, success in establishing supplementary relationship is what will be deemed as a most ideal and constructive idea. Understandably, such an understanding can afford practitioners more opportunities to explore and locate their strengths and weaknesses so that student-oriented approaches can be adopted for more productive and innovative improvements in students as Chan and Bray [9] advocates. Viewed this way, the relationship between schooling and tutoring can be constructively adjusted for positive competition where students' interest and progress are taken good care of.

As far as the macro environment is concerned, policymakers are put in a role required to strike a balance between the needs resulting from not only traditional examination-oriented Asian contexts [4, 31] but also assessment emphasized Western settings like the United Kingdom [32-33] where there arises a trend in language education of excessive quantifications and measurability. Great demand from students and parents prompt most of educational institutions, both schooling and tutoring, to prioritize the high-stakes examinations in their curriculum design, which might make them overlook the importance of the pragmatic usage. One participant in this study reckons that students may not be able to speak fluent English and communicate with foreigners effectively despite their full marks in the examination. Yung [6] also comments overemphasis of the language education in Hong Kong on the high achievement in the public examination, which fails to realize the communicative purposes in reality. The example of Hong Kong draws the attention of the public and this phenomenon seems common in different contexts globally [34-35]. Therefore, it is time the policymakers reflect on what purpose language education is. Nurturing one's communicative competence or training a machine for examination?

\section{Limitations}

A few limitations have to be acknowledged to reduce bias on the researchers' part. First, the writers admit that the demographic choice is not the most representative. The students are all senior students in a secondary school, so junior high and middle students who are equally required to learn English are ignored. Second, the students all come from a single secondary school; while their statements have brought insight into our current situation, it is by no means representative of the entire Hong Kong student body. Lastly, the writers want to acknowledge that we also are products of 
the Hong Kong education system, and are very familiar with English teaching even before conducting an objective, comprehensive research into the matter. This has the added advantage of being more persuasive in some areas, but researcher bias may still exist no matter how the writers want to eliminate it with our rationality.

\section{References}

[1] Bray, M. The shadow education system : private tutoring and its implications for planners. Paris: International Institute for Educational Planning, 2007.

[2] Zeng, K. Dragon gate: competitive examinations and their consequences. Zeng, K. (1999). Dragon gate: competitive examinations and their consequences. London: Cassell. London: Cassell, 1999.

[3] Bray, M. Researching shadow education: methodological challenges and directions. Asia Pacific Education Review. 11, 2010, Vol. 1.

[4] Bray, M and Lykins, C. Shadow Education: Private Supplementary Tutoring and Its Implications for Policy Makers in Asia. Mandaluyong City: Asian Development Bank., 2012.

[5] Bray, $M$, et al. Differentiated demand for private supplementary tutoring: Patterns and implications in Hong Kong secondary education. Economics of Education. 38, 2014, Vol. 1.

[6] Yung, K. W H. Learning English in the Shadows: Understanding Chinese Learners' Experiences of Private Tutoring. TESOL Quarterly. 49, 2015, Vol. 4, pp. 707-732.

[7] Bray, $M$ and Kobakhidze, M. Evolving ecosystems in education: The nature and implications of private supplementary tutoring in Hong Kong. Prospects, 45 (1), 465 481. Hong Kong. Prospects. 45, 2015, Vol. 1, pp. 465-481.

[8] Ireson, J. Private Tutoring: how prevalent and effective is it? London Review of Education. 2, 2004, Vol. 2, pp. 109-122.

[9] Chan, C and Bray, M. Marketized private tutoring as a supplement to regular schooling: Liberal studies and the shadow sector in Hong Kong secondary education. Journal of Curriculum Studies. 46, 2014, Vol. 3, pp. 361-388.

[10] Parasuraman, A, Zeithaml, A V and Berry, L L. A Conceptual Model of Service Quality and Its Implications for Future Research. Journal of Marketing. 49, 1985, Vol. 4, pp. 41-50.

[11] Kwok, P. Examination-Oriented Knowledge and Value Transformation in East Asian Cram Schools. Asia Pacific Education Review. 5, 2004, Vol. 1, pp. 64-75.

[12] Marimuthu, T, et al. Extra-school instruction, social equality and educational equality. Singapore: International Development Research Centre, 1991.

[13] Rohlen, P T. The society for for Japanese studies the Juku phenomenon: An exploratory essay. The Journal of Japanese Studies. 6, 1980, Vol. 2, pp. 207-242.

[14] Bray, M and Kwok, P. Demand for private supplementary tutoring: conceptual considerations, and socio-economic patterns in Hong Kong. Economics of Education Review. 22,
2003, Vol. 1, pp. 611-620.

[15] Burch, P. Hidden Markets: The New Education Privatization. New York: Routledge, 2009.

[16] Private expectations and public schooling: The growth of private tutoring in Australia. Watson, L. 2008. The national conference of the Australian Association for Research in Education.

[17] Kim, K K. Educational equality. [book auth.] J C Lee, Y S Kim and D Adams. Sixty years of Korean education. s.l.: Seoul National University Press, 2010, pp. 285-325.

[18] Hamid, O M, Susses, R and Khan, A. Private tutoring in English for secondary school students in Bangladesh. TESOL Quarterly: A Journal for Teachers of English to Speakers of Other Languages and of Standard English as a Second Dialect. 43, 2009, Vol. 2, pp. 281-308.

[19] Lee, B. The pre-university English-educational background of college freshmen in a foreign language program: A tale of diverse private education and English proficiency. Asia Pacific Education Review. 11, 2010, Vol. 1, pp. 69-82.

[20] Aurini, J. Educational Entrepreneurialism in the Private Tutoring Industry: Balancing Profitability with the Humanistic Face of Schooling. Canadian Review of Sociology/Revue Canadienne de Sociologie. 41, 2004, Vol. 4, pp. 475-491.

[21] Fitzsimmons, A J and Fitzsimmons, J M. Service management: operations, strategy, information technology. 7th. s.l.: McGraw-Hill., 2011.

[22] Silova, I, Budiene, V and Bray, M. Education in a Hidden Marketplace: Monitoring of Private Tutoring. New York: Open Society Institute, 2006.

[23] Marsh, C and Lee, C.-K J. Asia"s high performing education systems: The case of Hong Kong. New York: Routledge, 2014.

[24] Cohen, L, Manion, L and Morrison, K. Research Methods in Education. London: Routledge, 2007. Vol. 55.

[25] Scott, J. A matter of record: documentary sources in social research. Cambridge: Polity Press, 1990.

[26] Creswell, W J. Research design : qualitative, quantitative, and mixed methods approaches. 3th ed. s.1.: Sage, 2009.

[27] Gill, K S. Medium-of- Instruction Policy in Higher Education in Malaysia: Nationalism versus Internationalization. [book auth.] J Tollefson and A Tsui. Medium of Instruction Policies: Which Agenda? Whose Agenda? Mahwah: Lawrence Erlbaum, 2004, pp. 135-152.

[28] Spolsky, B and Hult, M F. The Handbook of Educational Linguistics. Oxford: Blackwell Publishing Ltd, 2008.

[29] Baker, C. Foundations of bilingual education and bilingualism. Bristol: Multilingual Matters, 2011.

[30] Kwo, O and Bray, M. Understanding the nexus between mainstream schooling and private supplementary tutoring: patterns and voices of Hong Kong secondary students. Asia Pacific Journal of Education. 34, 2014, Vol. 4, pp. 403-416.

[31] Carless, D. From testing to productive student learning: Implementing formative assessment in Confucian-heritage settings. New York: Routledge, 2011. 
[32] Frick, B. Fostering student creativity in the era of high-stakes testing. [book auth.] J Hattie and M E Anderman. International guide to student achievement. New York: Routledge, 2013, pp. 231-233.

[33] Bray, M., Kobakhidze, M. N., Zhang, W., \& Liu, J. The hidden curriculum in a hidden market place: relationships and values in Cambodia's shadow education system. Journal of Curriculum Studies. 50, 2018, pp. 435-455.
[34] Matsuoka, R. Inequality in Shadow Education Participation in an Egalitarian Compulsory Education System. Comparative Education Review. 64, 2018, pp. 565-586.

[35] Liu, J. \& Bray, M. Determinants of Demand for Private Supplementary Tutoring in China: Findings from a National Survey. Education Economics. 25, 2016, pp. 1-14. 